\title{
Effect of an acidic environment on a glass fibre reinforced polymer grid
}

\author{
Petr Šimůnek ${ }^{1, *}$, Petr Štěpánek ${ }^{1}$, Ivana Švaříčková ${ }^{1}$, Jan Prokeš $^{2}$, Ivana Laníková ${ }^{1}$, Petr \\ $\check{Z}_{\text {ítt }}{ }^{1}$ and João Pedro Miranda Mendes ${ }^{3}$ \\ ${ }^{1}$ Brno University of Technology, Institute of Concrete and Masonry Structures, Czech Republic \\ ${ }^{2}$ Prefa kompozity, Brno, Czech Republic \\ ${ }^{3}$ The Universidade Federal de Santa Catarina, Florianópolis, Brazil
}

\begin{abstract}
The article deals with the effect of an acidic environment on the mechanical properties of a Glass Fibre Reinforced Polymer (GFRP) grid. GFRP composites are prone to the absorption of surrounding media which are either of a liquid or gaseous state, and this may result in the degradation of their mechanical properties. The effect of an acidic environment is examined on specimens cut from a GFRP grid. The specimens were stored in an acidic bath $(\mathrm{pH}$ scale $2-2.5)$ for a period of 0 (reference specimen), 1000, 2000 and 6000 hours. The temperature of the acidic bath was $60^{\circ} \mathrm{C}$. The specimens were then tested using three-point bending and the interlamination shear strength test. During the tests, the load and deformation of the specimens were monitored and flexural strength instead and modulus of elasticity were determined. The characteristics of the specimens exposed to the acidic environment were compared with those of the reference specimen. The experiment demonstrated the effect an acidic environment can have on the properties of GFRP material.
\end{abstract}

\section{Introduction}

Today, composite GFRP (Glass Fibre Reinforced Polymer) grids are largely used at sewage plants, chemical plants, bridges and other similar infrastructure.

Composite grids have a long lifespan and are a suitable alternative to stainless or coated steel members especially in aggressive, corrosive environments. Such grids are used for staircase members, bridge and footbridge members, floors, structures built at port facilities, moles, etc. GFRP is a material which offers low weight and high strength.

The above-mentioned environments expose the grids to acidic solutions (for example, in wastewater treatment areas at chemical plants).

The flexural and low velocity impact response of a glass fibre/epoxy composite after immersion in hydrochloric acid $(\mathrm{HCl})$ and sodium hydroxide $(\mathrm{NaOH})$ was studied by A.M. Amaro et al. [1]. They tested composite laminates prepared in the laboratory from TEXIPREG glass fibre prepreg. The exposure time played a determining role in the

\footnotetext{
* Corresponding author: simunek.p@fce.vutbr.cz
} 
degradation of mechanical properties. They concluded that the alkaline solution appeared to be more aggressive than the acid solution, promoting the lowest flexural properties.

The effect of an acid solution on a Glass-reinforced plastic (GRP) Pipe (C glass) at normal and high temperatures was described by Mahmoud et al. [2], who demonstrated that flexural strength (and other characteristics such as hardness and Charpy impact resistance) depends on the time and type of acid. Flexural strength was not markedly affected within the first 30 days of immersion ( $20 \% \mathrm{HCl}$ acid concentration and room temperature), while during the next period the decrease in flexural strength was found to be around $10 \%$. In the case of an $\mathrm{HCl}$ solution combined with a high temperature $\left(100^{\circ} \mathrm{C}\right)$, all of the abovementioned characteristics decreased significantly.

The role of aging of the fibre-matrix interface of GFRP composites due to long-term immersion of sulfuric acid (six months) at high temperature and pressure $\left(90^{\circ} \mathrm{C}\right.$ and 15 bar) is discussed by M. Kanerva [3]. They conclude that experimental results show that the aging significantly affects tensile and flexural behaviour of glass fibre vinylester epoxy composites: tensile and flexural stiffness decreased $6-49 \%$ and ultimate strength values $13-$ $34 \%$.

The response of unperforated and perforated GFRP samples aged in a combined acidic and hot environment, under external stress (stress corrosion) and without external load conditions was investigated by S. Eslami [4].

The durability of commercial fibres (carbon, glass (E and ECR), and basalt) used in manufacturing FRP (fibre-reinforced polymer) reinforcing materials in terms of their chemical resistance to different corrosive environments, such as water and acid, alkaline, and saline solutions was studied by P. Cousin et al. [5]. They concluded that among the carbon, glass, and basalt fibres typically used in manufacturing of FRP bars, the carbon fibres were the strongest and most resistant to the various corrosive environments. The E-glass fibres had the lowest resistance to the acid environment and the highest fibre weight loss, which ranged from $21.9 \%$ to $35.1 \%$. These fibres also showed considerable reaction under alkaline exposure.

A significant part of the research is focused on the effect of the alkaline environment on FRP materials. This area mainly concerns FRP concrete reinforcement elements [6-8].

The specific characteristics of GFRP material strongly depend on the composition of the polymer and the amount, type and dislocation of fibres, and thus the material characteristics vary depending on the producer. It is possible to consider the behaviour of GFRP in a general sense, but every producer achieves more-or-less different test outputs.

\section{Testing of GFRP grid segments}

The tested grids PREFAGRID (moulded gratings; contain up to $40 \%$ glass fibre, Prefa Kompozity Corp.) are intended for use as structural members in engineering structures as well as technical parts of structures at manufacturing plants. Their application is especially in environments which are corrosive (aggressive) or have specific safety requirements with regard to electrical hazards. The upper surface of the grids was roughened with floured silica sand (a safety measure against slipping).

The tested specimens were made from a grid with mesh dimensions of $38 / 38$ and 30 $\mathrm{mm}$ of thickness. The geometry of the specimens is shown in Fig. 1. The grids are used as floor grids and are made of E-glass fibres and isophthalic resin.

The specimens were prepared in two sizes:

- $350 \mathrm{~mm}$ in length for flexural tests,

- $150 \mathrm{~mm}$ in length for short beam tests.

The specimens were exposed to the sulphur acid $(\mathrm{pH} 2-2.5)$ solution at $60^{\circ} \mathrm{C}$. The periods of immersion were 1000,2000 and 6000 hours. The test is analogous to the 
accelerated test method for alkali resistance of FRP bars, procedure A (ACI 440.3R - 12). Every set obtained 5 specimens. The cut surfaces were treated with a varnish coating in order to avoid the penetration of the solution along the glass fibres. Reference specimens (without exposure to the acid solution) were prepared for the comparison of outputs.
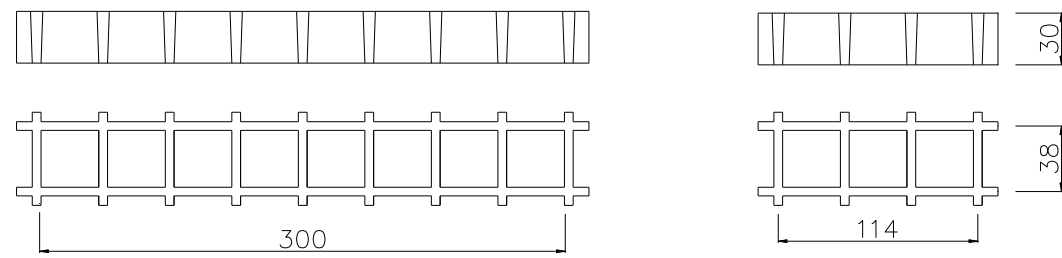

Fig. 1. Specimen geometry, longitudinal dimensions are distances between the supports (within the tests).

\subsection{Flexural tests}

Flexural tests (three-point bending) were carried out on the $350 \mathrm{~mm}$ long specimens. The distance between the supports was $300 \mathrm{~mm}$ (Fig. 2a). The observed values were deflection in the middle of the span and load force (monotone linear load deformation). The deflection was measured with help of the inductive displacement sensor, test configuration, Fig. 2.

Failure occurred due to rupturing of the glass fibre layer, along with delamination at the most tensioned areas, see Fig $2 b$, c.
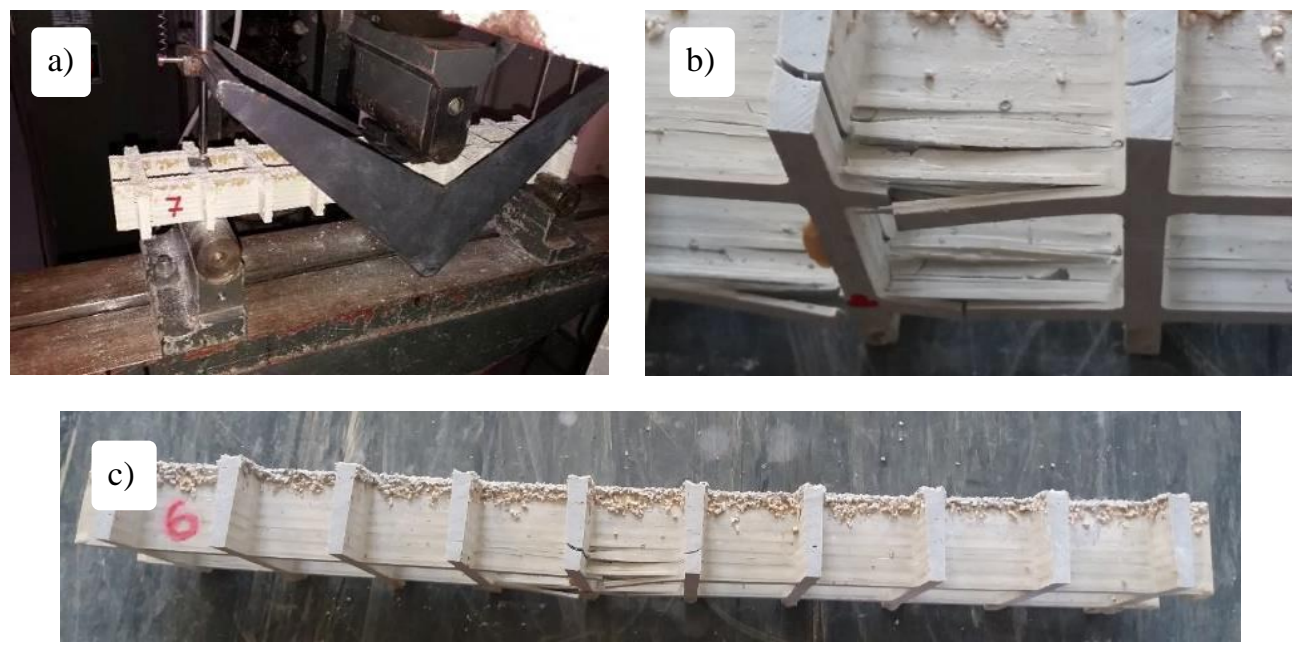

Fig. 2. Flexural test: a) Test configuration, b) Flexural failure mode, close-up view of damaged tensioned fibres, c) Flexural failure mode and overview.

The decrease in the modulus of elasticity (the slope of the load/deformation curves) and the decrease in the average value of the limit load capacity in relation to the period of immersion in the acidic environment are graphically shown in Fig. 3, and they are highly noticeable. 


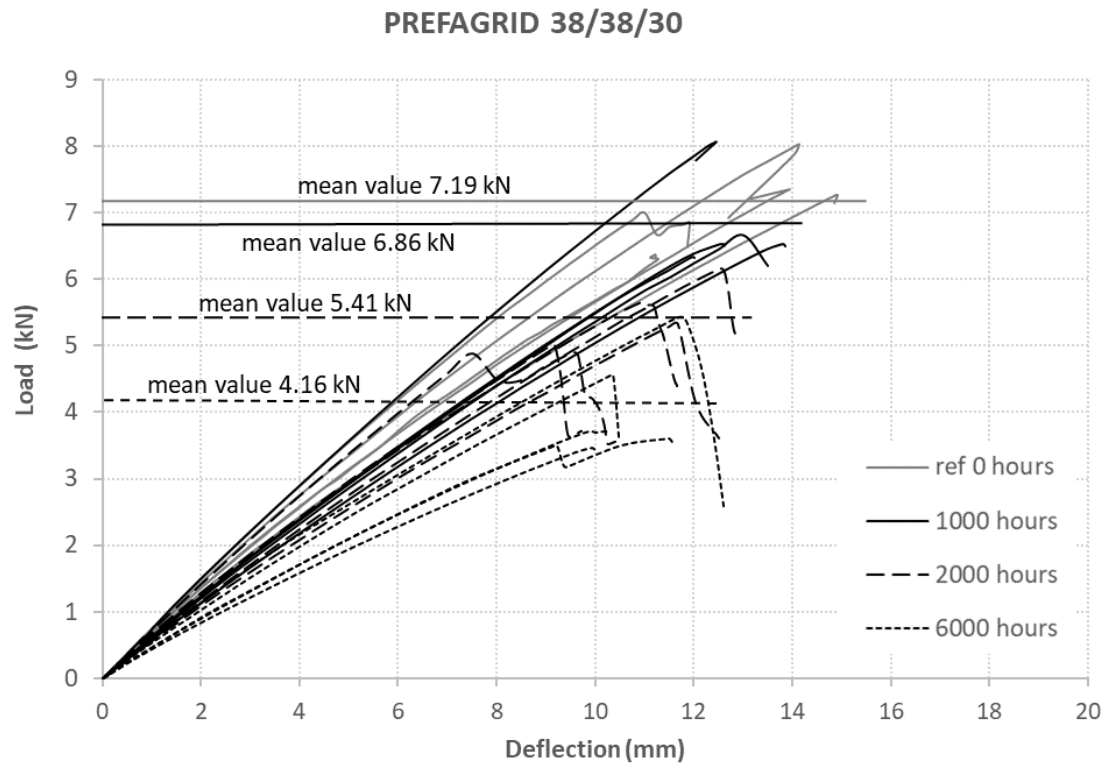

Fig. 3. Force - deflection diagram, flexure failure mode (tensile fibres).

\subsection{Short beam tests (interlaminar shear test)}

The short beam test (interlaminar shear test) was carried out to determine the strength of the matrix and/or the fibre/matrix interface. The test was performed according to the procedure in ASTM D 2344 [9], even though the specimen is not made from flat laminate. A similar procedure is also used for FRP reinforcing bars for concrete (ASTM D4475), application is shown e.g. in [10]. The distance between the supports was chosen with respect to the desired mode of failure, i.e. a crack parallel to the direction of the fibres. A set of tests were carried out in order to achieve the interlaminar failure mode (the appropriate span was approx. $100 \mathrm{~mm}$ ), see Fig. 4. The span length that was finally used was $114 \mathrm{~mm}$ due to the transverse ribbing.

The configuration of the test was the same as that of the three-point bending test with a short beam $(150 \mathrm{~mm})$, see Fig. 5 . The observed values were deflection and load force. The failure mode of each of the specimens took the form of delamination, i.e. interlaminar shear, see Fig. 4 and 5.

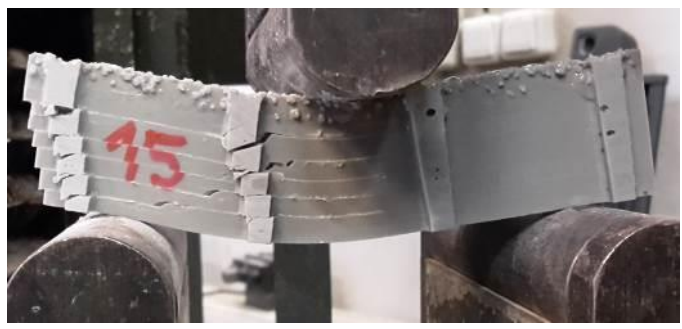

Fig. 4. The prepared test configuration - characteristic failure mode - interlaminar shear. 

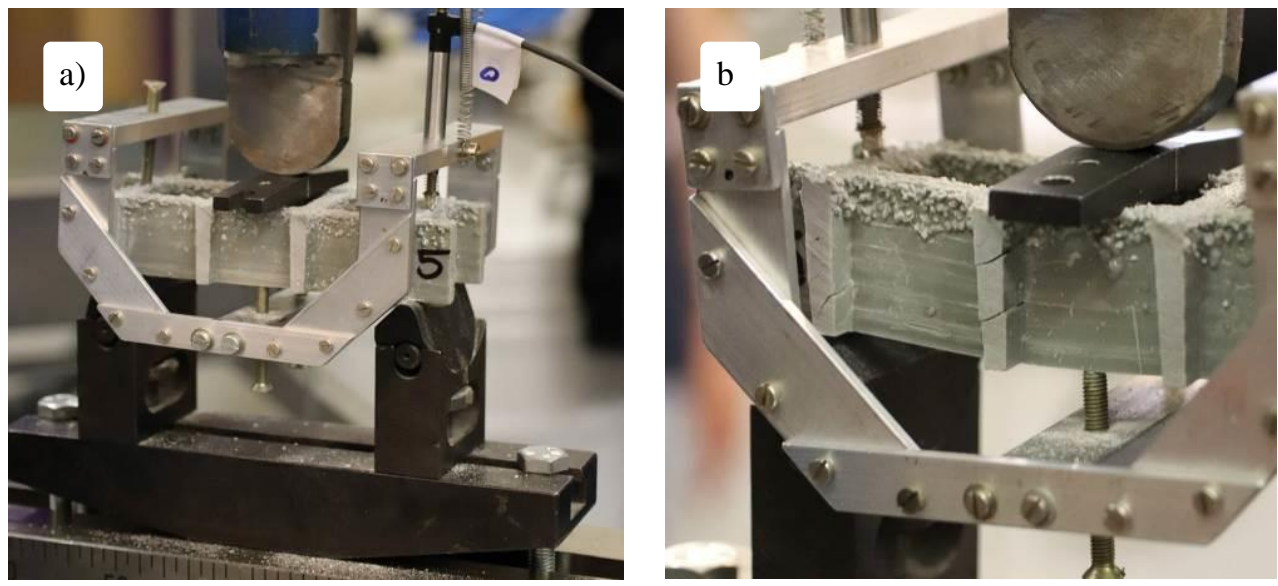

Fig. 5. Short beam test: a) Test configuration, b) Failure mode - interlaminar shear.

The decrease in the average value of the limit load capacity in relation to the period of immersion in the acidic environment is graphically shown in Fig. 6, and it is clearly visible.

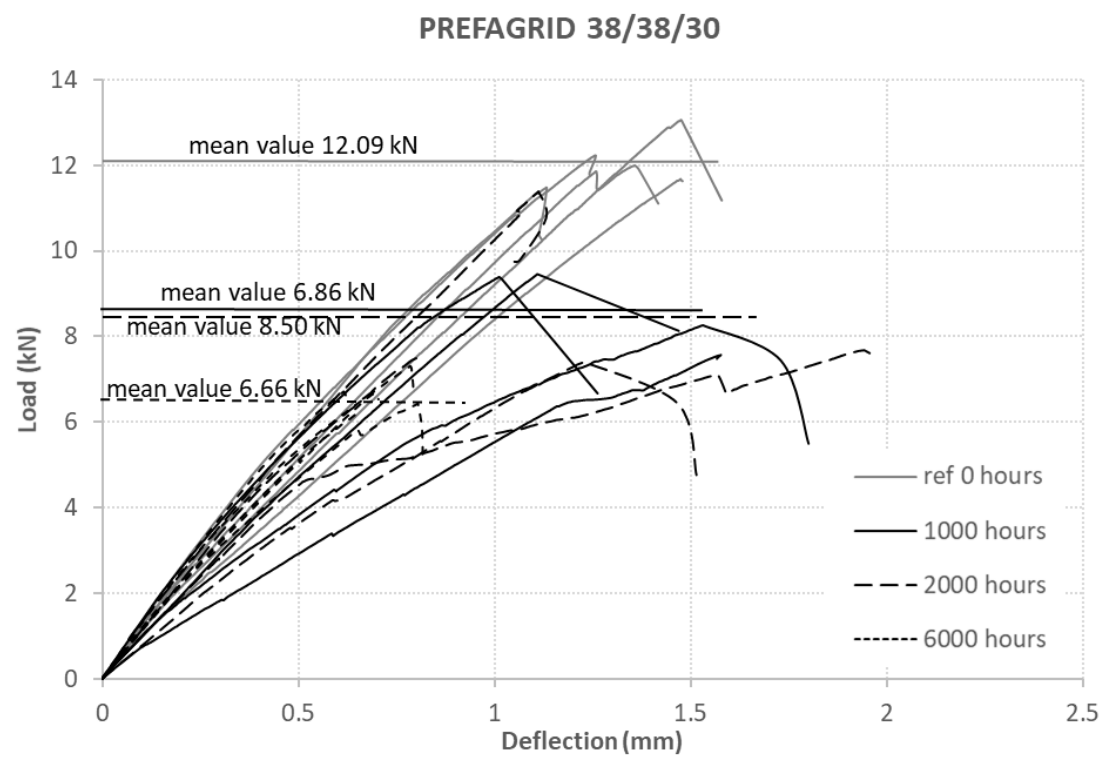

Fig. 6. Force - deflection diagram, interlaminar shear failure mode.

\subsection{Results and discussion}

The static behaviour of the reference and degraded specimens was monitored, and the modulus of elasticity, flexural tensile strength and shear strength (interlaminar) were studied. The test results show that the acidic solution causes the material characteristics of the GFRP grid to deteriorate. The change in the monitored quantities of the degraded specimens compared to the reference quantities (Tab. 1) is summarized in Tab. 2 and Fig. 7. With respect to the main aim to compare the effect of acidic environment on degradation, the observed values of the modulus of elasticity, tensile flexural strength and shear strength 
were calculated in a simplified way considering linearly elastic behaviour of the GFRP material. The spatial behaviour of the specimen was neglected.

Table 1. Determined material characteristics of the reference specimen.

\begin{tabular}{|c|c|c|c|}
\hline Characteristic & & Mean Value & CV \\
\hline Elastic modulus & $\mathrm{E}$ & $13533 \mathrm{MPa}$ & 0.088 \\
\hline $\begin{array}{c}\text { Tensile flexural } \\
\text { strength }\end{array}$ & $\sigma$ & $319 \mathrm{MPa}$ & 0.087 \\
\hline Shear strength & $\tau$ & $25 \mathrm{MPa}$ & 0.051 \\
\hline
\end{tabular}

Although there is a greater decrease in flexural tensile strength over time (Tab. 2), the effect of the decrease in elastic modulus is more significant. The load-bearing capacity of the grid is limited by the limit deflection, which is usually reached before the ultimate limit load is reached (with regard to the flexural tensile strength of the composite). Thus, the decrease in the modulus of elasticity has a more significant impact than the greater decrease in the strength of the composite.

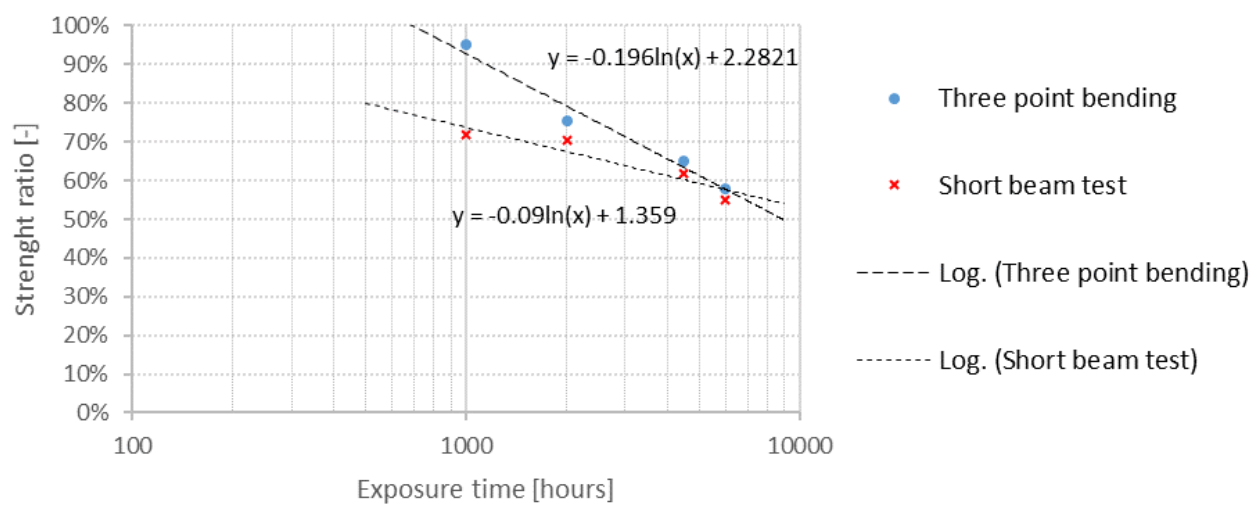

Fig. 7. Strength ratio - immersion (exposure) period.

Table 2. Decreases in the observed characteristics due to the effect of immersion in the acid solution ( $100 \%$ - reference specimen without exposure to the acid solution).

\begin{tabular}{|c|c|c|c|c|}
\hline \multicolumn{2}{|c|}{$\begin{array}{c}\text { Observed characteristic/period of } \\
\text { immersion }\end{array}$} & $\mathbf{1 0 0 0}$ & $\mathbf{2 0 0 0}$ & $\mathbf{6 0 0 0}$ \\
\hline \multirow{2}{*}{ Elastic modulus } & Mean value & $92.7 \%$ & $83.7 \%$ & $78.0 \%$ \\
\cline { 2 - 5 } & $\mathrm{CV}$ & 0.121 & 0.117 & 0.160 \\
\hline \multirow{2}{*}{$\begin{array}{c}\text { Flexural tensile } \\
\text { strength }\end{array}$} & Mean value & $95.0 \%$ & $75.3 \%$ & $57.8 \%$ \\
\cline { 2 - 5 } & $\mathrm{CV}$ & 0,103 & 0,094 & 0.199 \\
\hline \multirow{2}{*}{ Shear strength } & Mean value & $71.7 \%$ & $70.3 \%$ & $55.1 \%$ \\
\cline { 2 - 5 } & $\mathrm{CV}$ & 0.106 & 0.227 & 0.056 \\
\hline
\end{tabular}




\section{Conclusion}

Although composite materials (in this case GFRP grids) are generally resistant to corrosive environments, the type of impact of environmental aggressiveness must be considered during the design phase. The effect of an acidic solution on the values of material characteristics such as modulus of elasticity, flexural strength and interlaminar shear was studied in this paper.

The work demonstrated that long-term exposure to an acidic environment had a significant effect, which was intensified by the elevated temperature of the acid solution. All of the monitored quantities showed a significant decrease, and this should be considered during the design of structures expected to undergo long-term exposure to an acidic environment.

The presented results were obtained with the financial support of project TH02020548 "Advanced Assembled Composite Structures made of Pultruded Profiles" provided by the Technology Agency of the Czech Republic (TA CR). Some partial results were obtained within the project TA 04011047

"The development of continuous production technology of 3D composite elements".

\section{References}

1. A.M. Amaro, P.N.B. Reis, M.A: Netto, C. Louro, Polymer Degradation and Stability 98, 853-862 (2013)

2. M.K. Mahmoud, S.H. Tantawi, Polymer-Plastics Technology and Engineering 42, 677-688 (2007)

3. M. Kanerva, J. Jokinen, E. Sarlin, T. Pärnänen, M. Lindgren, M. Järventausta, J. Vuorinen, Composite Structures, 212, 524-534, (2019)

4. S. Eslami, F. Taheri, Corrosion Science, 69, 262-269, (2013)

5. P. Cousin, M. Hassan, P.V. Vijay, M. Robert, B. Benmokrane, Journal of Composite materials 53, 3651-3670 (2019)

6. P. Stepanek, O. Janus, F. Girgle, L. Bonarova, V. Kostiha, I. Rozsypalova, Procedia Structural Integrity 11, 12-19 (2018)

7. F. Micelli, A. Nanni, Construction and Building Materials, 18, 491-503 (2004)

8. F. Micelli, M. Corradi, M. A. Aiello, A. Borri, Appl. Sci. 7, 897 (2017)

9. ASTM D 2344 Standard Test Method for Short-Beam Strength of Polymer Matrix Composite Materials and Their Laminates, (2000)

10. O. Janus, F. Girgle, I. Rozsypalova, V. Kostiha, L. Bodnarova, P. Stepanek, J. Prokes, Acta Polytechnica CTU Proceedings 22, 38-47 (2019) 